\title{
Detailed numerical simulation of the auto-ignition of liquid fuel droplets
}

\author{
R. Stauch ${ }^{1}$, S. Lipp ${ }^{1}$, and U. Maas ${ }^{1}$ \\ ${ }^{1}$ Institute of Technical Thermodynamics, University of Karlsruhe(TH), \\ Kaiserstraße 12, 76131 Karlsruhe, Germany stauch@itt.mach.uni-karlsruhe.de, \\ lipp@itt.mach.uni-karlsruhe.de, maas@itt.mach.uni-karlsruhe.de
}

Summary. One and two dimensional numerical simulations of the auto-ignition process of single droplets of methanol and n-heptane in air are presented. Detailed models are used to simulate the transport processes as well as the chemical kinetics. Efficient numerical methods are implemented to reduce the computing time.

The influence of different ambient parameters on the ignition process is investigated. The ambient gas temperature turns out to be the physical parameter with the largest influence on the ignition delay time. With increasing ambient temperature the ignition delay time decreases. Furthermore, the ignition delay time decreases with increasing pressure following a power law. Two dimensional simulations show the almost exponential dependence of the ignition delay time on the velocity of a gas counterflow. If the counterflow is too strong, the flame is extinguished. Furthermore, the location of ignition is strongly affected by the counterflow velocity.

\section{Introduction}

A detailed understanding of droplet ignition and combustion is of interest in view of a reliable description of spray combustion. Especially a detailed understanding of the basic physical and chemical processes, like vaporization, transport and chemical kinetics, is required for reliable modelling. The simplest model of the fuel spray ignition process is the ignition of an ensemble of single fuel droplets. If microgravity droplet combustion is regarded, i.e. no gravitation, no relative motion of droplet and gas phase, the considered system can be assumed to have a spherical symmetry. Hence only a system of onedimensional conservation equations has to be solved. This regime is appropriate to investigate the basic physical and chemical processes, like vaporization, molecular transport and chemical kinetics and their interaction. Particularly for describing transient processes like the droplet ignition the understanding of this interaction is necessary. To account for a gas flow around the droplet or the ignition process of an array of droplets at least two-dimensional geometries have to be simulated. 
The combustion of a single liquid droplet in a quiescent atmosphere has been studied numerically. Numerical simulations have been presented for methanol droplets $[1,2,3]$ and n-heptane droplets $[4,5,6,7]$. Only a little number of studies do not assume spherical symmetry and nevertheless consider the physics of the droplets and the chemical processes in detail $[8,9,10,11,12,13]$. Few studies focus on the ignition process of fuel droplets of higher hydrocarbons $[5,6,7,14,15,16,17,18]$. Takei et al. [14], Nakanishi et al. [16] and Tanabe et al. [17] have determined ignition delay times of droplets experimentally. Tsukamoto et al. account for chemical kinetics by a one-step irreversible overall reaction [15]. Schnaubelt et al. investigate the ignition process of nheptane and n-decane experimentally and numerically $[6,18]$. Moriue et al. simulate the ignition of a fuel droplet in a closed volume [7]. However, the influence of the ambient gas temperature and the ambient pressure on the ignition process in the case of auto-ignition has not been investigated extensively based on detailed numerical simulations. With respect to technical applications, like gas turbines or combustion engines, the influence of ambient physical properties on the ignition process are of major interest. Parametric studies are performed to construct libraries of droplet combustion which can be used, e.g. in flamelet-like calculations of turbulent spray combustion. Parameters like the ambient gas temperature, pressure as well as the velocity of a gas counterflow are varied. In the case of the ignition of a droplet pair simulations with different droplet distances are performed. Studies of the ignition and combustion of methanol and n-heptane droplets in air are presented.

\section{Mathematical Model}

The presented model describes a fuel droplet surrounded by an ambient gas phase. This allows to formulate the governing set of compressible NavierStokes equations for a reactive system and equations of state for the gas phase and the liquid phase [19].

$$
\begin{array}{r}
\frac{\partial \rho}{\partial t}+\operatorname{div}(\rho \mathbf{v})=0, \\
\frac{\partial \rho_{i}}{\partial t}+\operatorname{div}\left(\rho_{i} \mathbf{v}\right)+\operatorname{div} \mathbf{j}_{i}=M_{i} \dot{\omega}_{i}, \\
\frac{\partial(\rho \mathbf{v})}{\partial t}+\operatorname{div}(\rho \mathbf{v} \otimes \mathbf{v})+\operatorname{div} \overline{\bar{p}}=0, \\
\frac{\partial \rho u}{\partial t}+\operatorname{div}\left(\rho u \mathbf{v}+\mathbf{j}_{q}\right)+\overline{\bar{p}}: \operatorname{grad} \mathbf{v}=0, \\
\text { gas : } \quad p=\frac{\rho}{\bar{M}} R T, \quad \text { liquid : } \quad \rho=\rho(T) .
\end{array}
$$

$t$ denotes the time, $\rho$ the density, $\mathbf{v}$ the velocity, $\rho_{i}$ the density of species $i, \mathbf{j}_{i}$ the diffusion flux density of species $i, M_{i}$ the molar mass of species $i, \dot{\omega}_{i}$ the 
molar scale rate of formation of species $i, \overline{\bar{p}}$ the pressure tensor, $u$ the specific inner energy, $\mathbf{j}_{q}$ the conductive heat flux density, $\bar{M}$ the mean molar mass and $R$ the universal gas constant.

The chemical kinetics of methanol is modelled by a detailed reaction mechanism of Chevalier and Warnatz [20], containing 23 chemical species and 166 elementary reactions. For n-heptane a detailed reaction mechanism of Golovitchev [21], containing 62 chemical species and 572 elementary reactions is used. The transport processes are also modelled in detail. Fourier's law is used to determine the heat fluxes. For the determination of the diffusion coefficients the approximation of Curtis and Hirschfelder [22] is used. Convection inside the droplet is neglected. The liquid phase properties are calculated based on the data correlations taken from Reid et al. [23]. The approximation of Latini et al. is used to calculate the heat conductivities, the approximation of Rowlinson and Bondi to calculate the specific heat capacities. The necessary properties to model the phase transition are also taken from Reid et al. [23]. The vapor pressure is calculated using the Wagner equation, and the enthalpy of vaporization is calculated by the correlation of Riedel and Watson.

A vaporization model accounts for the coupling of the liquid phase and the gas phase. A local phase equilibrium is modelled by interface equations.

$$
\begin{aligned}
\phi_{\text {vap }} & =\frac{-\sum_{j_{\text {vap }}} j_{j}^{g}-\sum_{j_{\text {vap }}} w_{j} \sum_{i} R_{i}+\sum_{j_{\text {vap }}} R_{j}}{\sum_{j_{\text {vap }}} \frac{p_{j} M_{j}}{p M}-1}, \\
0 & =\rho \cdot v_{n}-\phi_{\text {vap }}-\sum_{i} R_{i}, \\
0 & =\phi_{\text {vap }}\left(w_{i}-\epsilon_{i}\right)+j_{i}+w_{i} \sum_{j} R_{j}-R_{i}, \\
0 & =\sum_{i} \epsilon_{i} \cdot \phi_{\text {vap }} \cdot \Delta h_{\text {vap }, i}+j_{q}^{g}-j_{q}^{l} .
\end{aligned}
$$

$\phi_{\text {vap }}$ denotes the vaporization rate, $w_{i}$ the mass fraction of species $i, R_{i}$ the surface reaction rate of species $i, j_{v a p}$ the index of the vaporizing species, $p_{j}$ the partial pressure of species $j, p$ the pressure, $M_{j}$ the molar mass of species $j, \bar{M}$ the mean molar mass, $\rho$ the density, $v_{n}$ the normal velocity, $\epsilon_{i}=\dot{m}_{i} / \dot{m}$ the fraction of vaporizing mass, $j_{i}$ the diffusion flux density of species $i$ (gas phase), $\Delta h_{v a p, i}$ the enthalpy of vaporization of species $i$ and $j_{q}$ the heat flux density.

In the spherically symmetric case (1D) the equation system is transformed into modified Lagrangian coordinates to overcome difficulties with the discretization of the convective terms [24]. This allows to implement a low Mach number approximation easily and to replace the momentum equation by $\frac{\partial p(r)}{\partial r}=0$. The resulting equations are discretized by central differences on a non-equidistant grid. 

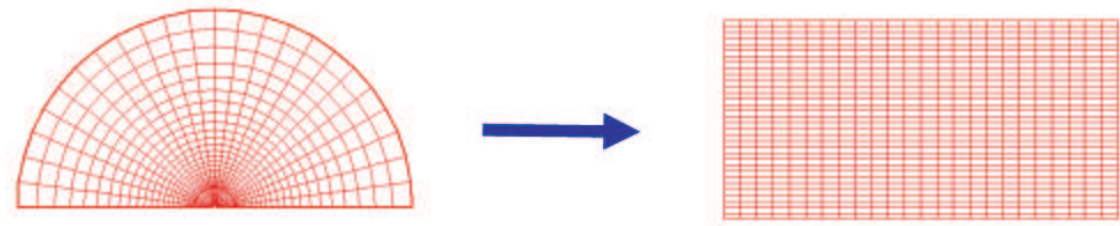

Fig. 1. Transformation into boundary-fitted coordinates

In the case of droplets in a convective environment (2D) the governing equations are transformed into generalized coordinates $\xi(x, y), \eta(x, y)$. This boundary-fitted curvilinear coordinate system is generated by the grid generator TOMCAT by solving a Poisson equation system after specification of the boundaries of the grid [25].

The spatial discretization is done by the method of lines using finite difference techniques. For the inviscid fluxes the flux vector splitting upwind scheme of Steger and Warming [26] is used. The flux vectors are split into subvectors by similarity transformations. The viscous fluxes are discretized using second order central differences in chain rule conservation law form [27].

In both cases $(1 \mathrm{D}$ and $2 \mathrm{D})$ one obtains a large system of ordinary differential and algebraic equations. The resulting differential-algebraic equation system is solved by the linearly implicit extrapolation method Limex [28]. This method was conceived for the solution of such large and stiff differentialalgebraic systems. In addition, efficient numerical methods are implemented for the calculation of the block tridiagonal and block nonadiagonal matrices and the solution of the linear equation systems [29]. Due to simultaneous perturbation of the sparse Jacobian the needed number of function evaluations does not depend on the number of grid points.

The program code is written in FORTRAN. Computations are performed on a regular single PC using LINUX as operating system. The simulations yielding to the presented results use the full capacity of the mentioned hardware. One dimensional simulations last for approximately ten CPU hours on grid with 50 points. Two dimensional simulations are performed on a grid with 40x20 points lasting forty CPU hours. Simulations of more complex systems are possible, because the program code can be easily parallelized by an appropriate compiler.

\section{Results and Discussion}

The knowledge of ignition delay times in the case of auto-ignition is of importance for many practical applications, e.g. Diesel engines or Lean Premixed Prevaporized (LPP) gas turbines [30]. First, the ignition delay times 
of single fuel droplets in a stagnant gas surrounding are presented for the fuels methanol and n-heptane. Subsequently studies of the ignition process of methanol droplets in a gas counterflow are presented.

\subsection{Ignition of fuel droplets in a stagnant gas phase}

Figure 2 shows the dependence of the ignition delay time of single methanol droplets on the ambient gas phase temperature, i.e. the parameter with the largest influence on the ignition delay time. The ignition delay times are presented for the temperature range from $1000 \mathrm{~K}$ to $2000 \mathrm{~K}$.

Figure 2 shows the typical exponential dependence of the ignition delay time on the ambient temperature for a homogeneous stoichiometric methanol/air mixture. In the case of the ignition of a single methanol droplet the ignition delay time also decreases exponentially with increasing temperature. Though, the decrease is not that strong as in the case of the homogeneous gas phase. The flattening of the temperature dependence is originated from the physical transport processes. With increasing temperature the physical transport speeds up not as rapidly as the chemical kinetics.

Because it is hard to control and to measure the initial conditions of single droplet experiments, simulations are performed for two different initial conditions in order to yield information on the sensitivity of the ignition delay time relating to the initial conditions. On the one hand no initial gaseous n-heptane is present (INI1), on the other hand simulations start with a small amount of prevaporized n-heptane in the gas phase (INI2).

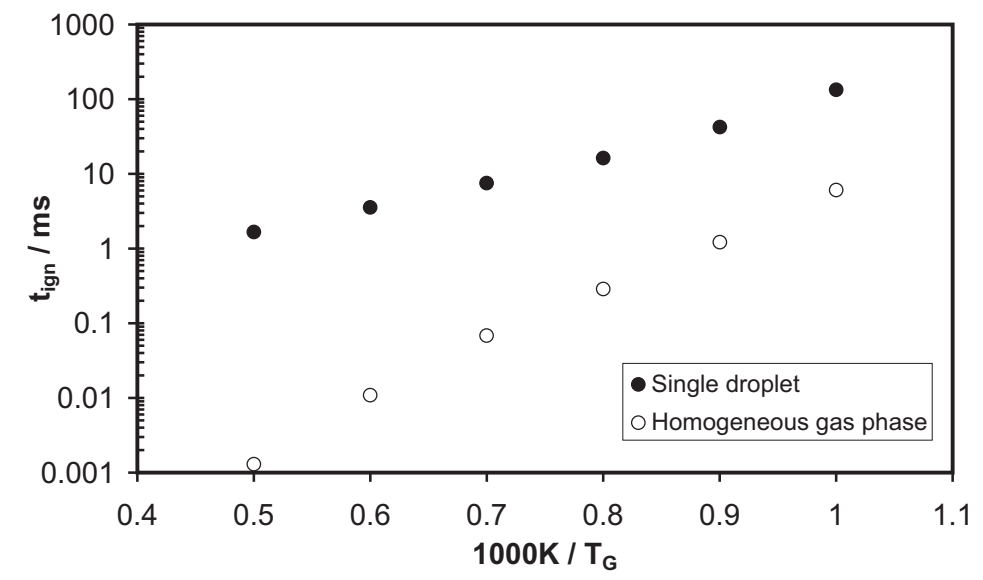

Fig. 2. Arrhenius plot of the dependence of the ignition delay time on ambient gas temperature (methanol, $p=7 \mathrm{bar}$, single droplets $r_{D}=200 \mu \mathrm{m}$, homogeneous gas phase $\lambda=1)$ 


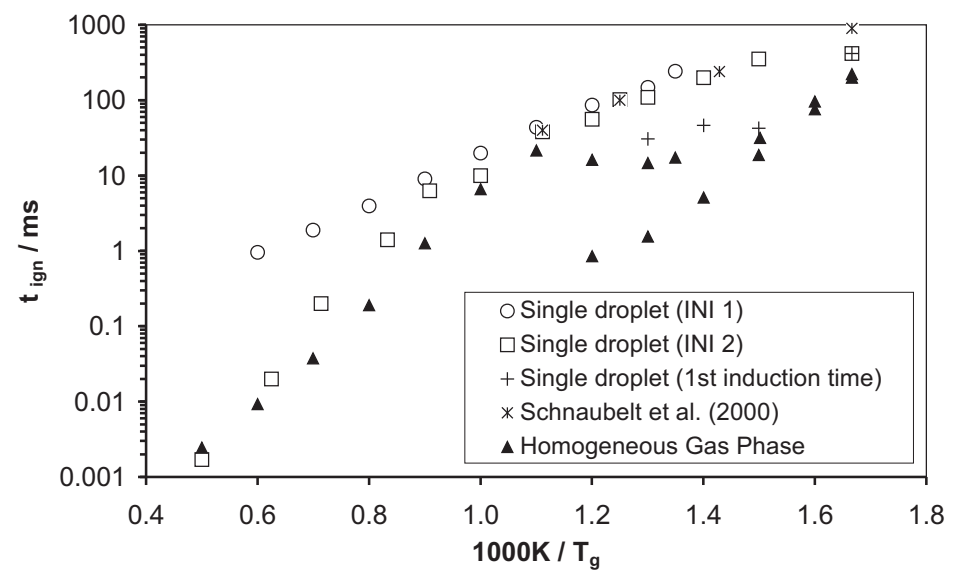

Fig. 3. Arrhenius plot of the dependence of the ignition delay time on ambient gas temperature (n-heptane, $p=7$ bar, single droplets $r_{D}=200 \mu \mathrm{m}$, homogeneous gas phase $\lambda=1)$

Figure 3 shows the dependence of the ignition delay time on the ambient gas phase temperature in the case of n-heptane droplets for a temperature range from $600 \mathrm{~K}$ to $2000 \mathrm{~K}$ with an ambient pressure of 7 bar and a droplet radius of $200 \mu \mathrm{m}$. Simulations are performed with the two different initial conditions (INI1, INI2) mentioned above. Between $650 \mathrm{~K}$ and $850 \mathrm{~K}$ a twostage ignition of the n-heptane droplet can be observed. Hence, not only the total ignition delay time but the first induction time are shown in figure 3. Additionally, the first and total ignition times of a homogeneous stoichiometric gaseous n-heptane/air mixture are included.

The typical temperature dependence of the ignition delay times can be seen for the case of a homogeneous n-heptane/air mixture. The ignition delay time depends strongly on the temperature below $700 \mathrm{~K}$ and above $900 \mathrm{~K}$. Between these two temperatures the ignition delay time increases with increasing temperature (NTC-behaviour). This behaviour of the total ignition delay times cannot be observed in the case of the igniting droplet. Solely the first induction time of the droplets shows nearly no temperature dependence (ZTC-behaviour) in the range of $650 \mathrm{~K}$ to $760 \mathrm{~K}$. For temperatures below $1000 \mathrm{~K}$ the temperature dependence appears to be almost the same for both initial conditions. Above $1000 \mathrm{~K}$ the dependence of the ignition delay time on the ambient temperature is stronger in the case of prevaporized n-heptane (INI2) than in the case of no initial gaseous n-heptane (INI1). This fact leads to much shorter ignition delay times for higher temperatures in the case of INI2. So the physical transport processes are determined to be rate limiting in this temperature range. In addition, ignition delay times of n-heptane droplets 


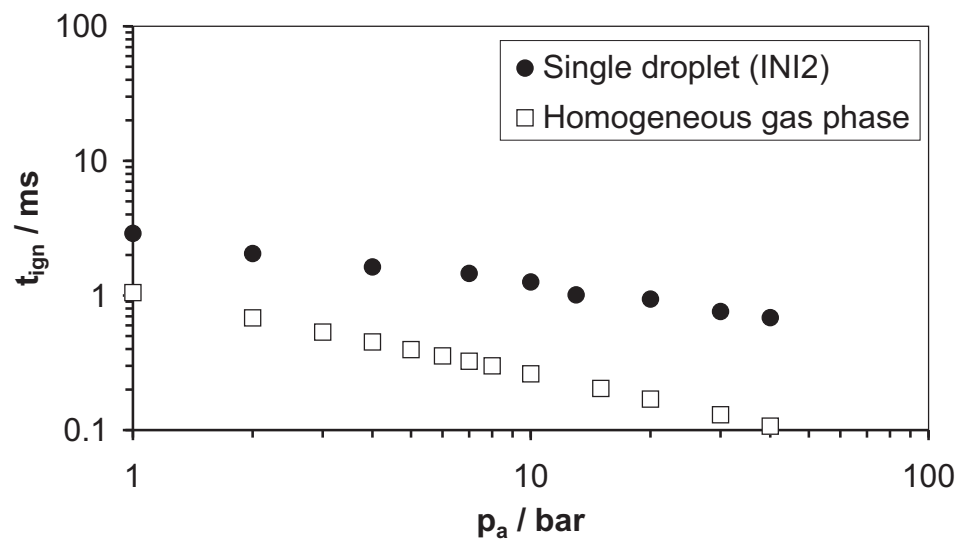

Fig. 4. Dependence of ignition delay time on ambient pressure (n-heptane, $T_{g}=$ $1200 \mathrm{~K}$, single droplets $r_{D}=50 \mu \mathrm{m}$, homogeneous gas phase $\lambda=1$ )

obtained by Schnaubelt et al. [18] are shown in figure 3. These ignition delay times show the same qualitative behaviour, whereas it should be noted that these results refer to different ambient conditions $\left(r_{D}=350 \mu \mathrm{m}, p=5 \mathrm{bar}\right)$.

Not only the dependence of the ignition delay on the ambient temperature, but also the dependence of the ignition delay time on the ambient pressure is of great interest. In figure 4 the pressure dependence of the ignition delay time is shown for the case of an n-heptane droplet in air with a droplet radius of $r_{D}=50 \mu \mathrm{m}$ and a gas temperature of $T_{g}=1200 \mathrm{~K}$. Additionally, again the pressure dependence of a homogeneous stoichiometric gaseous n-heptane/air gas mixture is included.

A decrease of the ignition delay time of an n-heptane droplet with increasing pressure can be observed. This decrease follows a power law with the exponent -0.4 (note, that the scaling of both axes of this figure is logarithmic).

$$
t_{\text {ign }}(p) \propto\left(\frac{p}{p_{0}}\right)^{-0.4}
$$

Other authors $[15,16]$ have determined almost the same behaviour. In the case of the homogeneous n-heptane/air mixture the qualitatively same behaviour is obtained. However, the decrease of the ignition delay time with increasing pressure is stronger, which results in another exponent of the power law of approximately -0.6 . 


\subsection{Ignition of fuel droplets in a convective gas phase}

In the following the influence of a gas counterflow on the ignition process of a methanol droplet is investigated. To study the sensitivity of this dependence on the initial conditions, again, simulations are performed with the two different initial conditions of no initial gaseous methanol (INI1) and prevaporized methanol in the gas phase (INI2).

The dependence of the ignition delay time on the velocity of a stationary gas counterflow is presented in figure 5 . No initial gaseous methanol is present (INI1), the droplet radius is $200 \mu \mathrm{m}$ and the gas temperature $T_{g}=1500 \mathrm{~K}$.

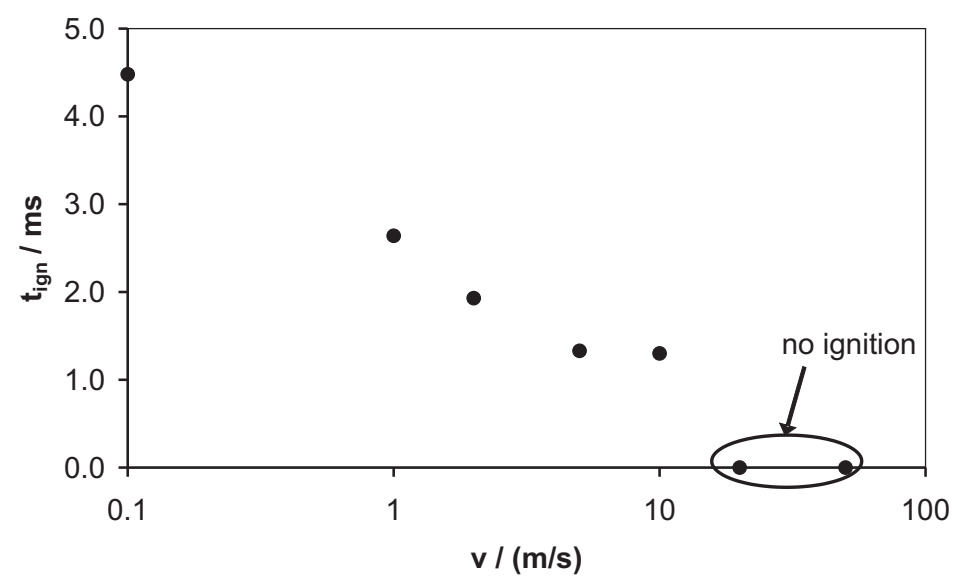

Fig. 5. Dependence of ignition delay time on droplet velocity (methanol, INI1, $\left.r_{D}=200 \mu \mathrm{m}, T_{g}=1500 K\right)$

The ignition delay time decreases with increasing counterflow velocity. Compared to the case of a stagnant gas environment the ignition delay time for a counterflow velocity of $10 \mathrm{~m} / \mathrm{s}$ is reduced by a factor of 4 . With an increasing droplet velocity the profiles are steepened and accordingly the diffusion fluxes become higher. The higher diffusion fluxes accelerate the processes of mixing and heat conduction. Therefore, a faster formation of an ignitable mixture at a sufficiently high temperature is promoted and the ignition delay time decreases. For velocities above $20 \mathrm{~m} / \mathrm{s}$ no ignition occurs any more. There, the local strain is so high, that the flame extinguishes.

In figure 6 , one can see the dependence of the ignition delay time on the counterflow velocity, if prevaporized methanol in the gas phase exists.

For counterflow velocities below $20 \mathrm{~m} / \mathrm{s}$ the ignition delay time remains almost constant despite the change of the velocity by a factor of 1000 . This behaviour is contrary to the case of no initial gaseous methanol (INI1), where 


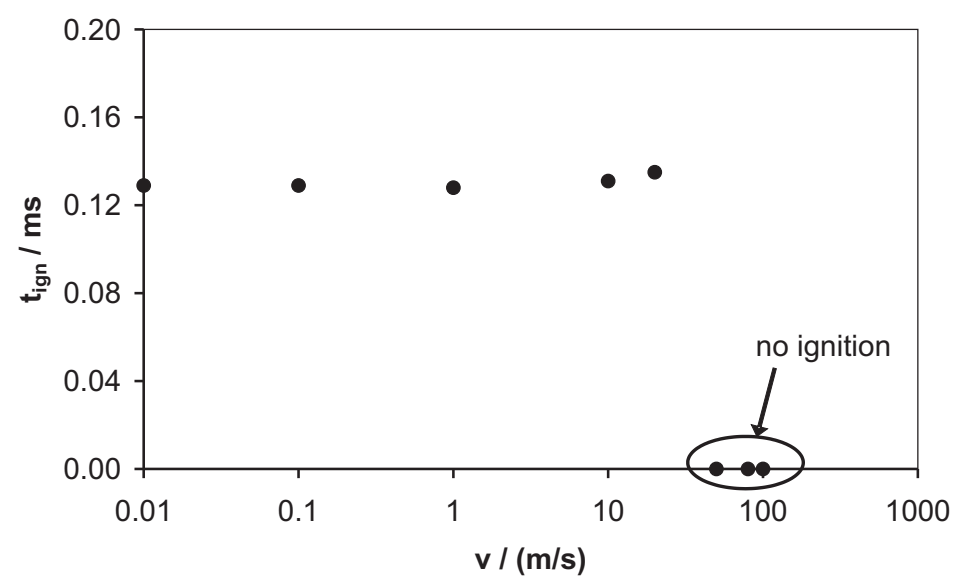

Fig. 6. Dependence of ignition delay time on droplet velocity (methanol, INI2, $\left.r_{D}=200 \mu \mathrm{m}, T_{g}=1600 \mathrm{~K}\right)$
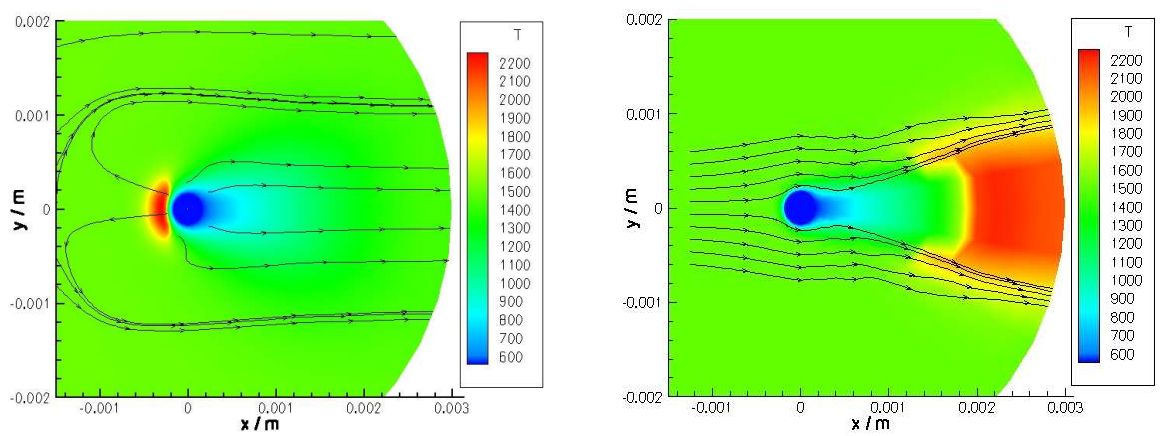

Fig. 7. Temperature profiles during the ignition process (methanol, $p=7 \mathrm{bar}, r_{D}=$ $\left.200 \mu \mathrm{m}, T_{g}=1500 \mathrm{~K}\right)$ : left: upstream ignition $(v=1 \mathrm{~m} / \mathrm{s})$; right: downstream ignition $(v=10 \mathrm{~m} / \mathrm{s})$

the ignition delay time is strongly affected by the gas counterflow velocity. The reason of this behaviour is supposed to be the fact, that if prevaporized methanol exists the transport processes are not that time-limiting like in the case of no initial gaseous methanol. If the velocity is larger than $50 \mathrm{~m} / \mathrm{s}$ no ignition occurs.

Other characteristical properties of the ignition and combustion process are also affected by the gas counterflow. In figure 7 the temperature profiles are shown for a lower velocity of $1 \mathrm{~m} / \mathrm{s}$ and a higher velocity of $10 \mathrm{~m} / \mathrm{s}$. at an 
early stage of ignition. In the case of the lower velocity the ignition process is initiated upstream, very close to the droplet surface. In contrast, the ignition occurs in the wake of the droplet for higher counterflow velocities.

\section{Conclusions}

The auto-ignition process of isolated fuel droplets in air is investigated. The simulations are performed for one and two dimensional geometries and with detailed models for the vaporization, transport process and chemical kinetics. The numerical model of the simulations is given in detail. Efficient numerical methods are devised to minimize computing time.

The influence of different ambient parameters on the ignition delay time is studied. The ignition delay time shows a strong dependence on the ambient gas temperature. The pressure dependence of the ignition delay time follows a power law with an exponent of -0.4 . Two dimensional simulations show the influence of a gas counterflow on the ignition process. With increasing counterflow velocity the ignition delay time decreases. In addition, the location of ignition is strongly affected by the gas counterflow. Though, the influence of almost all ambient parameters also depends on the initial conditions.

Further studies will focus on the auto-ignition process of multicomponent droplets, like n-heptane/iso-octane droplets, to achieve a better description of technical conditions. Two dimensional simulations will deal with the ignition process of droplet pairs.

\section{Acknowledgments}

The authors wish to thank the DFG for financial support in the frame of SFB 606.

\section{References}

1. Cho SY, Choi MY, Dryer FL (1990) Proc Combust Inst 23:1611-1617

2. Cho SY, Yetter RA, Dryer FL (1992) J Comput Physics 102:160-179

3. Stapf P (1992) Modellierung der Tröpfchenverbrennung unter Einschluß detaillierter chemischer Reaktion. PhD thesis. Universität Stuttgart

4. Cho SY, Dryer FL (1999) Combust Theory Model 3:267-280

5. Marchese AJ, Dryer FL, Nayagam V (1999) Combust Flame 116:432-459

6. Schnaubelt S, Moriue O, Eigenbrod C, Rath HJ (2001) Microgravity Sci Technol XIII/1:20-23

7. Moriue O, Mikami M, Kojima K, Eigenbrod C (2005) Proc Combust Inst 30: 1973-1980

8. Tsai JS, Sterling AM (1990) Proc Combust Inst 23:1405-1412 
9. Dwyer HA, Aharon I, Shaw BD, Niazmand H (1996) Proc Combust Inst 26:1613-1619

10. Stapf P, Dwyer HA, Maly RR (1998) Proc Combust Inst 27:1857-1864

11. Okai K, Moriue O, Araki M, et al (2000) Combust Flame 121:501-512

12. Aouina Y, Maas U, Gutheil E, Riedel U, Warnatz J (2001) Combust Sci Technol $173: 1-23$

13. Shaw BD, Dwyer HA, Wei JB (2002) Combust Sci Technol 174:29-50

14. Takei M, Tsukamoto T, Niioka T (1993) Combust Flame 93:149-156

15. Tsukamoto T, Okada H, Niioka T (1993) Trans Japan Soc Aeronaut Space Sci $35: 165-176$

16. Nakanishi R, Kobayashi H, Kato S, Niioka T (1994) Proc Combust Inst 25:447453

17. Tanabe M, Kono M, Sato J, et al (1995) Combust Sci Technol 108:103-119

18. Schnaubelt S, Moriue O, Coordes T, Eigenbrod C, Rath HJ (2000) Proc Combust Inst 28:953-960

19. Hirschfelder JO, Curtiss CF (1949) Proc Combust Inst 3:121-127

20. Chevalier C (1993) Entwicklung eines detaillierten Reaktionsmechanismus zur Modellierung der Verbrennungsprozesse von Kohlenwasserstoffen bei Hoch- und Niedertemperaturbedingungen. PhD thesis. Institut für Technische Verbrennung, Universität Stuttgart

21. Golovitchev V (2004) http://www.tfd.chalmers.se / valeri/MECH.html

22. Hirschfelder JO, Curtiss CF, Bird RB (1964) Molecular theory of gases and liquids. John Wiley \& Sons, New York:

23. Reid RC, Prausnitz JM, Poling BE (1989) The properties of gases and liquids. McGraw-Hill

24. Stauch R, Lipp S, Maas U (2005) Detailed numerical simulations of the autoignition of single n-heptane droplets in air (submitted)

25. Thompson JF, Thames FC, Mastin CW (1977) J Comput Physics 24:274-302

26. Steger JL, Warming RF (1981) J Comput Physics 40:263-293

27. Riedel U, Maas U, Warnatz J (1993) Comput Fluids 22:285-294

28. Deuflhard P, Hairer E, Zugck J (1987) Numerische Mathematik 51:501-516

29. Riedel U, Maas U, Warnatz J (1993) Impact Comput Sci Eng 5:20-52

30. Golovitchev V, Nordin N, Jarnicki R, Chomiak J (2000) SAE Paper 2000-011891 

